\title{
BIG HORN BASIN NATURAL RESOURCES DATA ASSESSMENT
}

\author{
Walter H. Eifert \\ Thomas A. Wesche \\ Stanley W. Anderson \\ University of Wyoming \\ Laramie
}

\section{Objectives}

The primary goal of this study is to establish the mechanism for a benchmark evaluation of the natural resource conditions of the Big Horn Basin prior to 1984. To accomplish this goal, the principal objectives of this investigation are threefold:

1. By means of literature and computer searches and extensive personal communication with key personnel of a variety of agencies, institutions, and other entities, systematically locate and establish the sources, nature, and availability of both quanitative and qualitative data from the Big Horn Basin in Wyoming concerning:
a. aquatic and riparian habitat
b. land and water uses
c. wildlife and fishery resources
d. water resources

2. Compile, standardize and key-word bibliographic information reviewed under Objective 1. Several geographic and descriptive retrieval terms will be assigned to each citation and these data will then be entered onto the FAMULUS system, a computerized bibliographic storage and retrieval package currently available at the University of Wyoming.

3. Develop a database "Users Guide" that would provide NPS personnel with information on how and where to access the system, procedures on how to generate efficient Search statements, and descriptions of available FAMULUS subroutines. Utilization of the FAMULUS information management system will provide the NPS with 1) a means to rapidly update the database, 2) an inexpensive technique for conducting initial Basin literature reviews, and, 3) a method to identify possible data gaps in those geographic areas within the Basin where deficiencies may occur.

\section{Methods}

The geographic area encompassed by this study is that portion of the Big Horn 
Basin watershed in Wyoming drained by the Big Horn River and its principal tributaries, e.g., the Wind, Greybull, Shoshoni, and Nowood Rivers.

To insure inclusion of all pertinent Basin literature, contacts with key personnel representing federal, state, local, university and private sector agencies were initiated. Included in the data collection process was the development and utilization of a data survey questionnaire, and extensive on-line computer literature searches. Both published and unpublished natural resources data secured from these sources were included in the documentation process.

Standardization of all Basin-related bibliographic information pursuant to F'A MULUS guidelines and specific NPS needs was then addressed. A standardized list of descriptors was utilized to insure organizational clarity and expedite the key-word process. To increase information retrieval efficiency, each citation was assigned three of four subject key-words and several geographic descriptors. Categorization by this technique should not only clarify the specific nature of each citation, by would provide the NPS with information on specific Basin areas where date deficiencies may occur. Bibliographic information retrieval utilizing both subject and geographic descriptors should, therefore, be useful to an NPS resource manager attempting to identify future research needs within the Big Horn Basin.

Following data standardization, all bibliographic information secured through the date of project termination will be entered onto the University of Wyoming's Cyber System. The FAMULUS program will be utilized to enter, edit, store and retrieve all included project data. The NPS will be furnished with computer printouts in several FAMULUS formats, two complete database tapes, and a "Users Guide" describing how and where to access the database, efficient use of the search subroutine, and a listing of all Basin-area contacts, useful for updating purposes.

\section{Results}

To date, Big Horn Basin natural resource data has been secured from all but one information repository. A "contact list" of key agencies and personnel conducting research within the Basin has been developed. Bibliographic information obtained from computer searches and data survey questionnaires has been documented.

Standardization of all documented bibliographic records is complete with the following format developed to best fulfill both FAMULUS and NPS database guidelines:

AUTH - Author of publication

SORT - Author rearrangement

YEAR - Year of Publication 


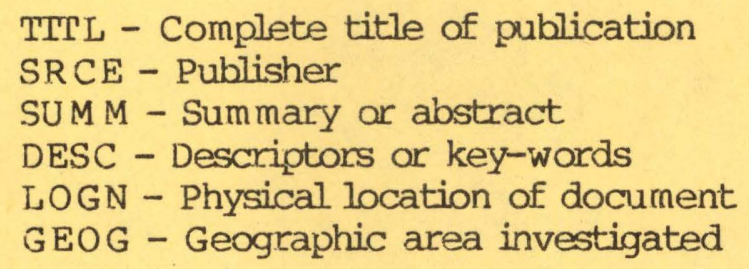

In addition to the nine "fields", e.g., AUTH, SORT, YEAR, etc., listed above, seven "dummy fields" per citation have been included to provide the NPS with future expansion capability should the need arise.

Database documentation specific to NPS needs has recently been completed. This information will be included in the "Users Guide", thereby providing NPS personnel with a step-by-step approach to database access, function and retrieval capability.

\section{Conclusion}

With the exception of one remaining information repository to be investigated, all criteria listed under Objective 1, have been fulfilled. To date, approximately 4,000 citations have been collected and standardizated in the previously presented format. This information is currently being entered onto the database and edited in 100 citation intervals. The database presently contains approximately 1,500 "clean" citations and will be completely functional at the end of the 1983 project year.

In reference to Objective 3, and NPS-Big Horn Basin Natural Resource Database Users Guide has been outlined and will be available for NPS use by April 30, 1984. Included in the Users Guide will be several viable alternatives for future system updates, step-by-step procedures on how and where to access the database, a list of key-word and geographic descriptors and a description of all FAMULUS subroutines available for NPS use. Presently, the primary focus of this study concerns data entry and editing as outlined by objective 2 . 